\title{
A 150-year reconstructed summer Asian-Pacific Oscillation index and its association with precipitation over eastern China
}

\author{
Ge Liu $\cdot$ Ping Zhao $\cdot$ Junming Chen
}

Received: 7 August 2009/Accepted: 10 May 2010/Published online: 25 May 2010

(C) The Author(s) 2010. This article is published with open access at Springerlink.com

\begin{abstract}
Reconstructing the long-term series of the East Asian summer monsoon (EASM) indices may help understand long-term variability of EASM and its associations with precipitation. In this study, the summer middle-upper tropospheric temperature over the Asian-North Pacific sector is reconstructed from sea level pressure during the past 150 years, and then an atmospheric thermal contrast between Asia and the North Pacific, called the AsianPacific Oscillation (APO) index, is calculated from the reconstructed temperature. The results show that the APO phenomenon may occur in the reconstructed temperature fields, and its index has a significant positive/negative correlation with SST over the extratropical North Pacific/ the tropical central-eastern Pacific in the past 150 years. The reconstructed summer APO index shows inter-decadal variability, with a positive phase in the $1870-1890$ s, the 1920s, and the 1940-1970s, indicating a stronger thermal contrast between Asia and the North Pacific, and with a negative phase in the $1860 \mathrm{~s}$, the 1900-1910s, and the 1980-1990s, indicating a weaker thermal contrast. Corresponding to a higher APO index in earlier decades of the twentieth century, there are more rainfall to the south of the Yangtze River and over North China and less rainfall over the Huaihe River valley. In the recent decades, however, more- and less-rain belts shifted southwards when
\end{abstract}

\section{G. Liu $\cdot$ J. Chen}

Chinese Academy of Meteorological Sciences,

Beijing 100081, China

\section{P. Zhao $(\square)$}

National Meteorological Information Centre,

China Meteorological Administration,

Beijing 100081, China

e-mail: zhaop@cma.gov.cn the APO index is higher. During 1850-1900, the reconstructed APO index also showed a significant positive correlation with precipitation in some regions of North China.

\section{Introduction}

The East Asian summer monsoon (EASM) is an important phenomenon in the Asian-western North Pacific region, characterized by the prevalence of the lower-tropospheric southwesterly or southeasterly winds that transport moisture from the Indian or Pacific Oceans to eastern China. Consequently, EASM brings large amounts of precipitation to the monsoon region. The anomalous behavior of EASM often results in flood or drought disasters (Lau and Li 1984; Krishnamurti and Surgi 1987; Ding 2004). In the past 50 years, a prominent long-term change of summer rainfall occurred over eastern China, with a wetting trend over the middle-lower valleys of the Yangtze River and a drying trend over the Yellow River valley (e.g., Weng et al. 1999; Gong and Ho 2002; Zhao et al. 2010). This inter-decadal change of the EASM precipitation has resulted in the frequent occurrence of flood disasters over eastern China. For example, in the 1990s, five serious floods occurred in the lower valley of the Yangtze River during 1991, 1995, 1996, 1998, and 1999 because of excessive rainfall over southern China (Zhao et al. 2010).

On the decadal scale, the rainfall variability over eastern China is modulated by EASM, and the latter is linked to Eurasian and Tibetan conditions, tropical sea surface temperature (SST), and the Arctic sea ice (e.g., Chang et al. 2000; Yang and Lau 2004; Zhang et al. 2004; Zhao et al. 2004; Zhan and Li 2008; Wang et al. 2009). However, the effects of these factors on EASM are complicated. One 
possibly dominates over the other during a period, but their relative dominance may be different during another period. This result leads to the changeability of EASM in time. Thus, studies on the basis of longer-range data can provide further insights into long-term variability of EASM and the associated mechanisms.

Because of the lack of long-term observational data over eastern China during the past 150 years, a variety of temperature or precipitation proxies was applied to reveal long-term variability of EASM over the past 150 years. Utilizing tree-ring reconstructions as a proxy of precipitation over China and Korea, Liu et al. (2003) investigated the variations of the EASM precipitation over the past 160 years. Yang et al. (2006) revealed a long-term varying trend of EASM on the basis of rainfall in the Yunnan Province of China reconstructed from the historical documents of the Qing Dynasty. Using the $\delta^{18} \mathrm{O}$ record of tree rings (sensitive to summer precipitation) in the Helan Mountains of Northwest China, Liu et al. (2008) analyzed the variation of the EASM intensity during 1878-1997.

Meanwhile, some authors have paid attention to reconstructions of atmospheric circulation. For example, based on the canonical correlation analysis, Barnett and Preisendorfer (1987) presented a technique of principle component regression. Using this technique, Luterbacher et al. (1999) reconstructed the North Atlantic Oscillation index for the period 1675-1990 from instrumental and documentary proxy pressure, temperature, and precipitation records. Klein and Dai (1998) used the method called the "pointwise" regression for reconstructing the monthly mean 700-hPa geopotential height field during 1947-1992. Moreover, Gong and Wang (2000) and Gong et al. (2007) also applied this method to the reconstruction of the monthly mean $500-\mathrm{hPa}$ geopotential height field since the late nineteenth century, analyzing the relationship between the Pacific/North America teleconnection pattern and El NiñoSouthern Oscillation. Using the reconstructed height field (Gong and Wang 2000), Mu et al. (2001) further examined variability of the western Pacific subtropical high and its association with precipitation over eastern China during 1880-1999. These reconstructions have helped understand variability of atmospheric circulation and the related mechanisms over the past 150 years.

The variability of the Asian monsoons is closely associated with changes in the thermal contrasts between the Asian continent and its adjacent oceans (e.g., Murakami and Ding 1982; Webster and Yang 1992; Li and Yanai 1996; Zhao et al. 2007). The Asian-Pacific Oscillation (APO) represents an out-of-phase teleconnection pattern in middle-upper tropospheric temperature between Asia and the extratropical North Pacific (Zhao et al. 2007) and can be captured by some climate models (Zhao et al. 2009). The
APO index essentially indicates a thermal contrast between Asia and the extratropical North Pacific, reflecting well the interannual and inter-decadal variability of major EASM circulation systems and associated rainfall in the recent decades (Zhao et al. 2007, 2008, 2009). Thus, investigating this thermal contrast is useful in understanding the varying characteristics of the EASM circulation and rainfall.

With this purpose in mind, we reconstruct the horizontal field of summer middle-upper tropospheric $(500-200 \mathrm{hPa})$ mean zonal temperature anomalies on the basis of sea level pressure (SLP) since 1850, which are used to calculate the reconstructed APO index and to examine its relationships with summer precipitations over eastern China over the past 150 years. The rest of this paper is organized as follows: In Section 2, we describe datasets, reconstruction methods, and APO; in Section 3, we perform temperature reconstructions and calculate the APO index; in Section 4, we examine the relationship between the reconstructed APO index and the North Pacific SST to further verify the reliability of the reconstructions; the relationship between the reconstructed APO index and precipitation over eastern China over the past 150 years is presented in Section 5; finally, a summary and discussion are provided in Section 6.

\section{Data, method, and definition of the APO index}

\subsection{Data}

In this study, we employ the 1850-2004 SLP analysis data of the Hadley Centre (HadSLP2) with a resolution of $5^{\circ}$ in both latitude and longitude (Allan and Ansell 2006), the 1948-2004 monthly mean air temperature from the National Centers for Environmental Prediction (NCEP) reanalysis dataset with a resolution of $2.5^{\circ}$ in both latitude and longitude (Kalnay et al. 1996), the 1901-2002 precipitation data with a resolution of $0.5^{\circ}$ in both latitude and longitude from the Climatic Research Unit (CRU) of the University of East Anglia (New et al. 2000), the 19012000 rainfall observations in Beijing and Tianjin, China from National Climate Center of China Meteorological Administration, and the 1854-2004 SST data with a resolution of $0.5^{\circ}$ in both latitude and longitude (Smith et al. 2007). We also use the 1724-1924 summer rainfall in Beijing that was reconstructed by combining royal official records of the Qing Dynasty with the instrumental data (Zhang and Liu 2002). The 1900-2004 monthly Pacific Decadal Oscillation (PDO) index was downloaded from the website http://jisao.washington.edu/pdo/PDO. latest. Moreover, the summer refers to the period from June to August. 


\subsection{Method}

Principle component regression (PCR) (Barnett and Preisendorfer 1987) and "pointwise" regression (PTR) (Klein and Dai 1998) methods are used to reconstruct temperature from SLP. The singular value decomposition (SVD) method may be used to detect a relationship between pairs of meteorological fields (Prohaska 1976).

PCR is a regression method, in which principal component analysis is used to estimate regression coefficients and principal components (PCs) of an independent variable field, rather than the independent variable field itself, are regressed on the dependent variables. When the independent variables themselves are linearly correlated (namely multicollinearity), the least-squares regression coefficients would be inaccurately estimated. In the PCR technique, a subset of the PCs in the regression is selected to eliminate the multicollinearity of the independent variables and to mostly remain their original information (Massy 1965). In our reconstruction, the first 14 PCs of the independent variables are introduced in the regression and account for more than $99 \%$ of the total variance.

The PTR method is briefly presented as follows. For each grid point on the field of dependent variables, one may establish a linear regression equation between the dependent variable value at this grid point and the values at all grid points of the independent variable field by using stepwise regression. Repeating this process, we may obtain a series of regression equations for an entire field of dependent variables and reconstruct the entire field. Because the stepwise regressions are applied to the values on the field of dependent variables point by point, this method is called "pointwise" regression. The PTR method may remain some teleconnection information and increase reconstruction skills (Gong et al. 2007). In our reconstructions, each regression equation is significant at the $95 \%$ confidence level, which assures the reliability of our reconstructions.

The SVD method applies an empirical orthogonal function analysis to the field of time cross-correlation coefficients between two variable fields (Prohaska 1976). For each eigenvalue, we may obtain a set of eigenvectors and corresponding amplitude coefficients, which are dependent on the spatial characteristics of the two meteorological fields, respectively. Since the SVD method may maximize areas of a high correlation at each of the corresponding grids of the original fields' dominant modes, the areas of significant correlation can be isolated in terms of the explained mean-square correlation (Prohaska 1976).

Moreover, correlation and regression analyses are applied in investigating the relationships between pairs of variables. The statistical significance discussed in this study is assessed using the Student's $t$ test and is at the 95\% confidence level unless otherwise stated. When the time series show serial correlations, the degrees of freedom possibly decrease, and the confidence level is therefore overestimated. Thus, we consider the reduction in degrees of freedom by using the number of effective data points $\left(N_{\mathrm{EFF}}\right)$ (Quenouille 1952), that is,

$N_{\mathrm{EFF}} \cong \frac{N}{1+2 \sum_{k=1}^{K} r_{1}(k) r_{2}(k)}$,

where $N$ is the total number of data points, and $r_{1}(k), r_{2}(k)$ are the lag- $k$ autocorrelations of two time series. In this study, the confidence level of the correlation analysis is calculated by means of the effective number of degrees of freedom.

\subsection{The summer APO index}

Before reconstructing air temperature fields and calculating thermal contrasts between Asia and the North Pacific, it is necessary to review the APO phenomenon. APO is identified as a summer zonal teleconnection pattern over the extratropical Asian-Pacific region, showing an out-ofphase relationship in the middle-upper tropospheric (MUT, 500-200 hPa) mean $T^{\prime}$ between Asia and the North Pacific (Zhao et al. 2007), in which $T^{\prime}=T-\bar{T} ; T$ is the temperature, and $\bar{T}$ is the zonal mean value of $T$. When the MUT $T^{\prime}$ is higher over Eurasia, it is generally lower over the North Pacific and vice versa. The formation of APO is explained by a zonal vertical circulation in the extratropical Asian-Pacific region (Zhao et al. 2009). The APO index may be defined as a difference of the MUT temperature between Asia $\left(60-120^{\circ} \mathrm{E}, 15-50^{\circ} \mathrm{N}\right)$ and the North Pacific $\left(180-120^{\circ} \mathrm{W}, 15-50^{\circ} \mathrm{N}\right)$ (Zhao et al. 2007), that is,

APO index $=T_{60-120^{\circ} \mathrm{E}, 15-50^{\circ} \mathrm{N}}^{\prime}-T_{180-120^{\circ} \mathrm{W}, 15-50^{\circ} \mathrm{N}}^{\prime}$

It is seen from Eq. 2 that the APO index reflects a zonal thermal contrast between Asia and the North Pacific. During 1958-2001, the APO index showed the interdecadal variability and was closely associated with some major circulation systems over the East Asian monsoon region, reflecting rainfall variability over eastern China (Zhao et al. 2007).

\section{Reconstructions of summer MUT mean temperature and APO index}

\subsection{Reconstruction of temperature}

In order to reconstruct the summer MUT mean $T$ field from SLP, we first examine the relationship between $T^{r}$ and 
SLP. The SVD analysis between $T^{\prime}$ and SLP or SLP' is performed over the region $0-70^{\circ} \mathrm{N}, 30^{\circ} \mathrm{E}-90^{\circ} \mathrm{W}$ during $1961-2000$, in which SLP $^{\prime}=$ SLP $-\overline{\mathrm{SLP}}$; $\overline{\mathrm{SLP}}$ is the zonal mean of SLP.

The result shows that the first SVD mode between $T^{\prime}$ and $\mathrm{SLP}^{\prime}$ accounts for $45 \%$ of the squared covariance, with a correlation coefficient of 0.73 (significant at the 99.9\% confidence level) between two time series of the expansion coefficients of $T^{\prime}$ and $\mathrm{SLP}^{\prime}$, which suggests that the first mode of $T^{\prime}$ is highly correlated with that of SLP'. Figure 1a shows the heterogeneous correlation pattern for the first mode of MUT $T^{\prime}$. In the figure, the positive correlations mainly appear at the middle and lower latitudes of the Asian continent, while the negative correlations mainly appear at these latitudes of the North Pacific. The heterogeneous correlation pattern for the first mode of SLP' (Fig. 1b) shows that the negative correlations cover most of the Asian continent, while the positive correlations dominate the central and eastern Pacific. Clearly, the increase (decrease) of MUT temperature over Asia (the North Pacific) is accompanied by a decrease (increase) of SLP over Asia (the North Pacific), which implies a close relationship between $T^{\prime}$ and SLP' during summer. Similarly, we also examine the relationship between $T^{\prime}$ and SLP. The result shows that the first SVD mode between $T^{\prime}$ and SLP (figures not shown) accounts for $42 \%$ of the squared covariance, with a correlation coefficient of 0.70 between two time series of the expansion coefficients of $T^{\prime}$ and SLP. These values are slightly smaller than those between $T^{\prime}$ and SLP', which implies that the skill of the SLP'-related reconstruction is slightly higher than of the SLP-related reconstruction. Therefore, using $\mathrm{SLP}^{\prime}$ from the HadSLP2 data and $T^{\prime}$ from the NCEP reanalysis data, we may reconstruct summer MUT mean $T^{\prime}$ from SLP', in which 40 years (from 1961 to 2000) are selected as a calibration period.

A reconstruction skill may be estimated using a reduction of error (RE) (Cook et al. 1994; Gong et al. 2007), in which RE is defined as follows

$\mathrm{RE}=1-\frac{\sum\left(T^{\prime}-\widehat{T}^{\prime}\right)^{2}}{\sum\left(T^{\prime}-T_{c}^{\prime}\right)^{2}}$,

where $T^{\prime}$ is called the observed for convenience; $\widehat{T}^{\prime}$ is the reconstructed $T^{\prime} ; T_{\mathrm{c}}^{\prime}$ is the mean value of $T^{\prime}$ in the calibration period. RE ranges from $-\infty$ to +1 . When $R E \leq$ 0 , the reconstruction has no skill; when $R E=1$, the reconstruction is perfect. Some studies showed that when $\mathrm{RE}>0.2$, the reconstruction is acceptable (e.g., Gong et al. 2007). In the present study, we choose 0.4 as a critical value of RE, that is, when RE $>0.4$, the reconstructed field is statistically believable. (a)

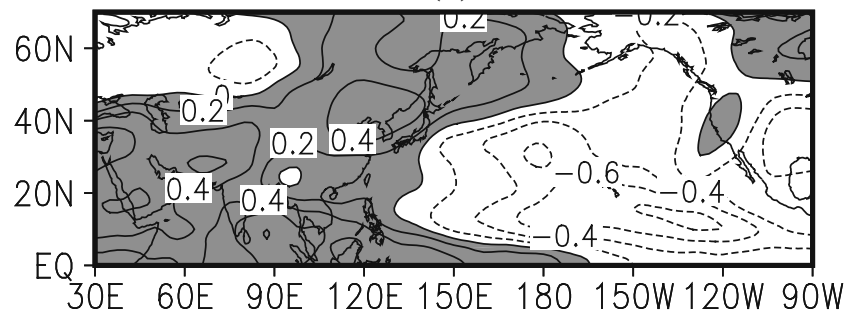

(b)

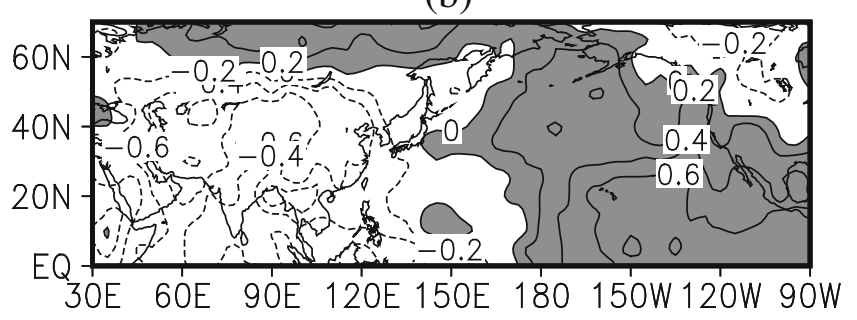

Fig. 1 Heterogeneous correlation pattern for the first mode of $T^{\prime}$ (a) and $\mathrm{SLP}^{\prime}$ (b) for the period 1961-2000, the shaded area is greater than 0

Figure 2 shows horizontal distributions of RE for the PCR and PTR reconstructions. It is seen that there is the similar pattern between Fig. 2a and b, with the positive values exceeding 0.4 over most of the extratropical AsianPacific region. Compared to Fig. 2a, the positive values above 0.4 in Fig. $2 b$ cover a larger region. Calculation further shows that for the PTR reconstruction, the values of RE above 0.4 account for $63 \%$ of the total grid points over two boxes shown in Fig. 2, far more than 35\% of the PCR reconstruction, which suggests that the region with a higher reconstruction skill (RE $>0.4)$ is larger in PTR than in PCR. Thus, it is more appropriate to reconstruct the MUT $T$ field

(a)

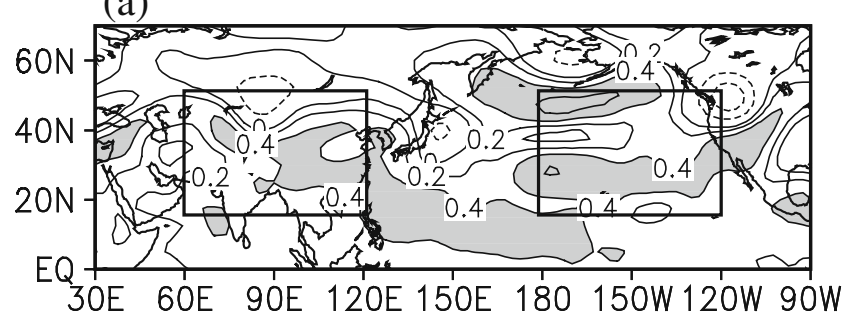

(b)

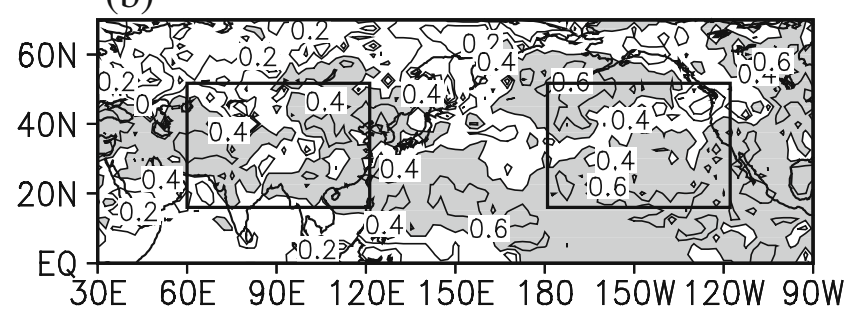

Fig. 2 Distributions of RE during 1951-2004 for a PCR and b PTR, in which two boxes represent the regions for Asia and the Pacific, respectively. The shaded areas are for $\mathrm{RE} \geq 0.4$ 


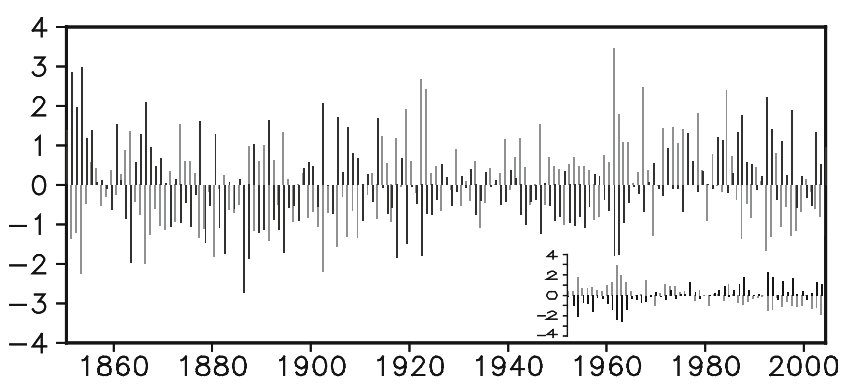

Fig. 3 The reconstructed summer Asian (grey bars) and Pacific (black bars) $T^{\prime}$ indices during 1850-2004, with their corresponding observations during 1951-2004 in the nested figure

by means of the PTR method. In the following section, the PTR method is used in the $T^{\prime}$ reconstruction.

\subsection{The reconstructed APO index and its variability}

In order to examine whether the APO phenomenon occurred in the past 150 years, based on the reconstructed $T^{\prime}$, we calculate its regional averages with $\mathrm{RE}>0.4$ over Asia and the extratropical North Pacific, which are located in the regions $150-50^{\circ} \mathrm{N}, 60-120^{\circ} \mathrm{E}$, and $15-50^{\circ} \mathrm{N}, 180-$ $120^{\circ} \mathrm{W}$, respectively, called the reconstructed Asian and Pacific $T^{\prime}$ indices (Fig. 3). The reconstructed Asian (Pacific) $T^{\prime}$ index showed the varying feature similar to the observed during 1951-2004, with a correlation coefficient of 0.82 (0.92) between the reconstructed and observed Asian (Pacific) indices, significant at the 99\% (99.9\%) confidence level. This result confirms the reliability of the reconstructed Asian (Pacific) $T^{\prime}$ index. Moreover, for the period 1850-2004, there is a significant out-of-phase relationship between the reconstructed Asian and Pacific $T^{\prime}$ indices, with a correlation of -0.66 (significant at the $99.9 \%$ confidence level). This negative correlation is still seen during 1850-1960, with a correlation coefficient of -0.71 (significant at the $99.9 \%$ confidence level), consistent with that of the observed during the recent 50 years (Zhao et al. 2007). This result also demonstrates the existence of APO during the past 150 years.

Based on the definition of the APO index shown in Eq. 2, we calculate the difference between the reconstructed Asian and Pacific $T$ indices, called the reconstructed APO index. Figure 4 shows the reconstructed APO index during 1850-2004 and the observed APO index during 19512004. In the figure, the reconstructed APO index showed a decreasing trend during 1951-2004, similar to the observed. The correlation coefficient between the reconstructed and observed APO indices is 0.93 for the calibration period 1961-2000, significant at the $99.9 \%$ confidence level, and the correlation coefficient is 0.74 for the verification period 1951-1960, significant at the $98 \%$ confidence level. This result shows that the reconstructed

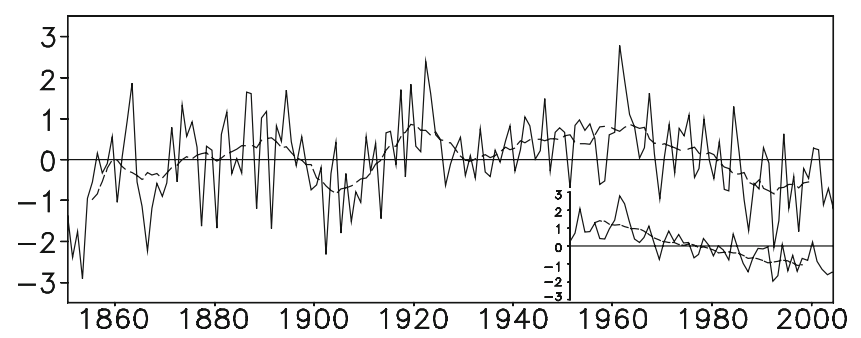

Fig. 4 The reconstructed summer APO index (solid line) and its 11year running average (dashed line) during 1850-2004, with the observed summer APO index (solid line) and its 11-year running average (dashed line) during 1951-2004 in the nested figure

APO index is statistically believable. Moreover, it is seen from Fig. 4 that the 11-year running average of the reconstructed APO index shows inter-decadal variability. Positive phases of the APO index occurred mainly in the 1870-1890s, the 1920s, and the 1940-1970s, reflecting a stronger EASM circulation, and negative phases emerged mainly in the 1860s, the 1900-1910s, and the 1980-1990s, reflecting a weaker EASM circulation.

Following Christiansen et al. (2009), we further compare the reconstructed APO index with the observed one through exploring the relative low-frequency variability of the reconstructed APO index by using its 11-year running average. The result shows that the relative low-frequency amplitude and trend are -0.48 and -0.27 , respectively. The negative values indicate that our reconstruction method to some extent underestimates the trend and amplitude of the low-frequency variability, which is similar to the underestimation in many other methods (Christiansen et al. 2009). Thus, the reliability of the reconstructed APO index should further be verified through some existing physical relationships between APO and other climate elements (e.g., precipitation over eastern China and SST over the Pacific) (Zhao et al. 2007, 2008, 2009).

\section{Variations of the Pacific SST associated with APO}

The previous studies showed that the summer APO index is highly correlated with SST over the extratropical North Pacific (35-45 $\mathrm{N}, 150^{\circ} \mathrm{E}-150^{\circ} \mathrm{W}$ ) (Zhao et al. 2008, 2009; Zhou et al. 2010), with a correlation coefficient of 0.52 (significant at the 99\% confidence level) during 1954-2003 (Zhou et al. 2010). After removing their linear trends, the correlation coefficient is 0.58 . This relationship could be explained well by atmospheric circulation and surface heat budget over the extratropical North Pacific (Zhou et al. 2010). Moreover, the APO index is also highly correlated with SST over the tropical eastern Pacific $\left(10^{\circ} \mathrm{S}-10^{\circ} \mathrm{N}\right.$, $130-80^{\circ} \mathrm{W}$ ) during summer (Zhao et al. 2008, 2009). These correlations suggest that when the summer APO 


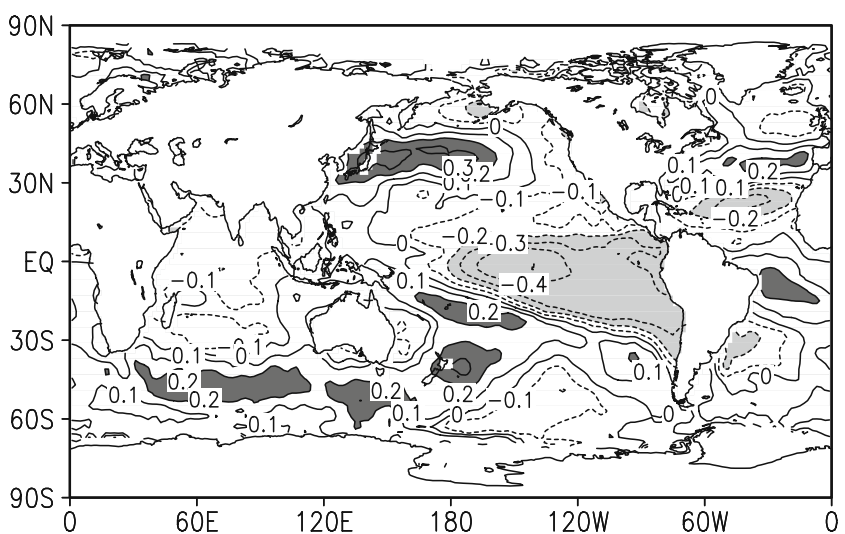

Fig. 5 Correlation coefficient between the reconstructed summer APO index and concurrent SST during 1854-1960. The shaded areas are at the $95 \%$ confidence level

index is higher, SST increases over the extratropical North Pacific and decreases over the tropical eastern Pacific. Such high correlations between the APO index and the Pacific SST may also be used to physically verify the believability of the reconstructed APO index.

Figure 5 shows the correlation coefficient between the reconstructed summer APO index and the concurrent SST during 1854-1960. In the figure, significant positive correlations appear at the mid-latitudes of the centralwestern North Pacific, with the maximum value of 0.30 (significant at the $99 \%$ confidence level). This result shows that the summer APO index is positively correlated with the extratropical North Pacific SST, consistent with that during 1961-2000 (figure not shown) and the previous results (Zhao et al. 2008, 2009; Zhou et al. 2010). Because the variability of the extratropical North Pacific SST is characterized by the PDO (Mantua et al. 1997), we also use the PDO index to indicate the variability of the extratropical Pacific SST, in which the PDO index is derived as the leading principal component of SST anomalies over the North Pacific to the north of $20^{\circ} \mathrm{N}$ (Mantua et al. 1997). The correlation coefficient between the PDO and reconstructed APO indices is -0.54 during
1900-2004, significant at the $99.9 \%$ confidence level. This negative correlation shows that corresponding to a higher APO index, the PDO index is lower, which reflects a higher SST over the extratropical North Pacific, further supporting the result from Fig. 5. Moreover, it is also seen from Fig. 5 that significant negative correlations appear over the tropical central-eastern Pacific, with the central value of -0.40 , significant at the $99 \%$ confidence level.

Summing up, the relationships between the reconstructed summer APO index and the concurrent SST over the extratropical and tropical Pacific were stable over the past 150 years. When the APO index is higher, SST is higher over the extratropical North Pacific and is lower over the tropical central-eastern Pacific. Clearly, although our reconstruction underestimates to some extent the trend and the amplitude of low-frequency variability (see Section 3.2), this underestimation does not affect the relationship between the APO index and SST over the Pacific. This stable relationship also verifies the reliability of the reconstructed APO index.

\section{Variations of rainfall over eastern China associated with APO}

The APO index may well reflect variations of atmospheric circulation and rainfall over the East Asian monsoon region during summer (Zhao et al. 2007, 2008). Their studies showed that when the summer APO index is higher, the lower-tropospheric (at $850 \mathrm{hPa}$ ) anomalous southerlies prevail in the subtropics and middle latitudes of East Asia, indicating a stronger thermal contrast between Asia and the extratropical North Pacific and a stronger EASM circulation, and strengthening the transport of warm and wet air toward North China. Accordingly, summer precipitation remarkably increases over North China and South China, while it decreases over the Yangtze River valley.

Figure 6a shows the regressed summer CRU precipitation against the reconstructed APO index during 1961-
Fig. 6 Regressed CRU summer precipitation $(\mathrm{mm})$ against the reconstructed (a) and observed (b) APO indices during 19612000. The shaded areas are at the $95 \%$ confidence level (a)

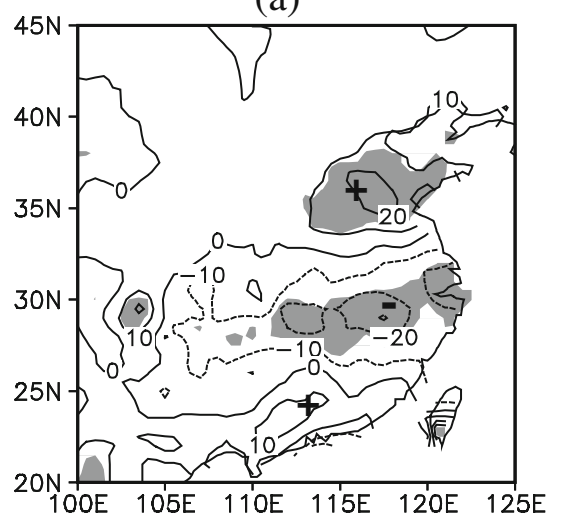

(b)

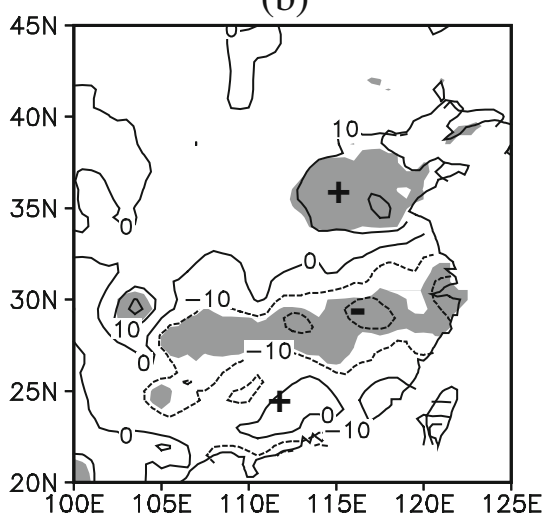


2000. In the figure, positive anomalies of precipitation appeared over North China and South China, while negative values occurred over the Yangtze River valley. This result shows a " +-+ " pattern in the summer precipitation anomaly over eastern China, consistent with a basic feature of the summer precipitation anomaly over eastern China (Ding et al. 2008), the pattern associated with the observed APO index (Fig. 6b), and the previous study (Zhao et al. 2007). Thus, the reconstructed APO index can reflect the anomalies of summer precipitation over eastern China during the recent 40 years, which further verifies the reasonability of our reconstruction.

This relationship between APO and rainfall also occurred in earlier decades of the past 100 years. Figure 7 shows the regressed CRU summer rainfall against the reconstructed APO index during 1901-1960. In the figure, positive values appeared to the south of the Yangtze River (with a central value near $27^{\circ} \mathrm{N}$ ) and over North China (with a central value near $40^{\circ} \mathrm{N}$ ), while weak negative values appeared over the Huaihe River valley. The precipitation anomaly also showed a +-+ pattern. Compared with the current pattern (shown in Fig. 6), however, the positive and negative values in Fig. 7 consistently appeared in a more northward position, indicating a systematically northward shift of more and less rain belts over eastern China during 1901-1960. The time series of precipitation in Beijing $\left(39^{\circ} 48^{\prime} \mathrm{N}, 116^{\circ} 28^{\prime} \mathrm{E}\right)$ and Tianjin $\left(39^{\circ} 05^{\prime} \mathrm{N}, 117^{\circ} 04^{\prime} \mathrm{E}\right)$ are used to support the results from the CRU summer rainfall. A correlation analysis shows that the APO index is positively correlated with summer rainfall in Beijing and Tianjin, with the correlation coefficients of 0.35 and 0.31 during 1901-1960 (significant at the 95\% confidence level), respectively. This result is consistent with that in Fig. 7.

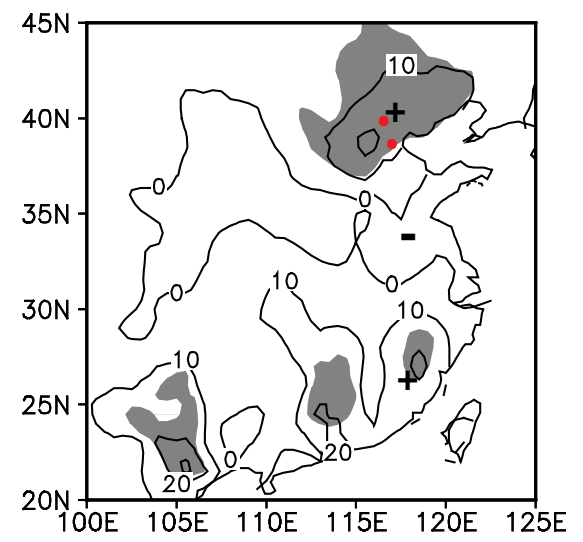

Fig. 7 Regressed CRU summer precipitation (mm) against the reconstructed APO index during 1901-1960, in which northern and southern dots indicate the positions of Beijing and Tianjin, respectively. The shaded areas are at the $95 \%$ confidence level
Moreover, we perform a 40-year running correlation analysis between the summer APO index and the concurrent rainfall over eastern China during 1901-2000, in which the correlation is calculated during 1901-1940, then 1902$1941, \ldots$, until 1961-2000 in turn. Accordingly, we obtain temporal variations of the correlation pattern between the APO index and rainfall. Figure 8 shows a time-latitude cross section of the running correlation along the longitudes $112-123^{\circ} \mathrm{E}$. In the figure, summer precipitation anomalies over eastern China associated with APO distinctly exhibited a +-+ pattern during the periods $1901-1940$ to $1923-1962$, with a positive correlation staying south of $30^{\circ} \mathrm{N}$ and north of $36^{\circ} \mathrm{N}$ and a negative correlation staying near $35^{\circ} \mathrm{N}$. This feature is similar to that shown in Fig. 7. However, the +-+ pattern shifted southwards during the periods 1948-1987 to 1961-2000, with a positive correlation appearing at 35-40 $\mathrm{N}$ and near $25^{\circ} \mathrm{N}$ and a negative correlation appearing over the Yangtze River valley. This feature is similar to that in Fig. 6. This change in two correlation patterns (shown in Figs. 6 and 7) was gradually ongoing, not showing an abrupt feature.

Because of the limits of the observed precipitation at meteorological stations of China before 1900, the reconstructed Beijing summer precipitation from the Qing Dynasty's royal official records during 1724-1904 (Zhang and Liu 2002) is used to examine the relationship between the reconstructed APO index and precipitation over North China. Figure 9 shows the reconstructed APO index and the Beijing summer precipitation during 1850-1900. In the figure, on the decadal scale, less precipitation in Beijing generally corresponded to a lower APO index during the 1850 s to the mid 1870 s, while more precipitation generally corresponded to a higher APO index during the late $1870 \mathrm{~s}$ to the late $1890 \mathrm{~s}$. The correlation coefficient between the APO index and Beijing precipitation is 0.46 during 1850 1900 , significant at the $95 \%$ confidence level. This result possibly implies that when the APO index is higher (corresponding to a stronger EASM circulation), more

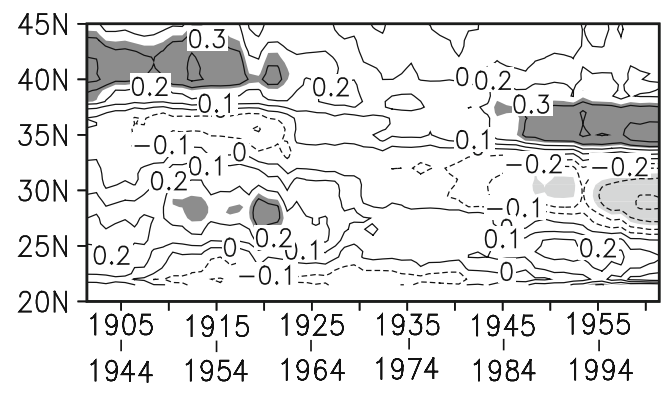

Fig. 8 Time-latitude cross section of the 40-year running correlation between the APO index and CRU summer precipitation along 112 $123^{\circ} \mathrm{E}$ during $1901-1940$ to $1961-2000$. The shaded areas are at the $90 \%$ confidence level 
Fig. 9 Time series (solid lines) and its 11-year running average (dashed lines) for summer precipitation in Beijing (upper) and the reconstructed summer APO index (lower) during 18501900 , in which the horizontal line indicates the summer climatological mean precipitation $(524 \mathrm{~mm})$ in the upper figure

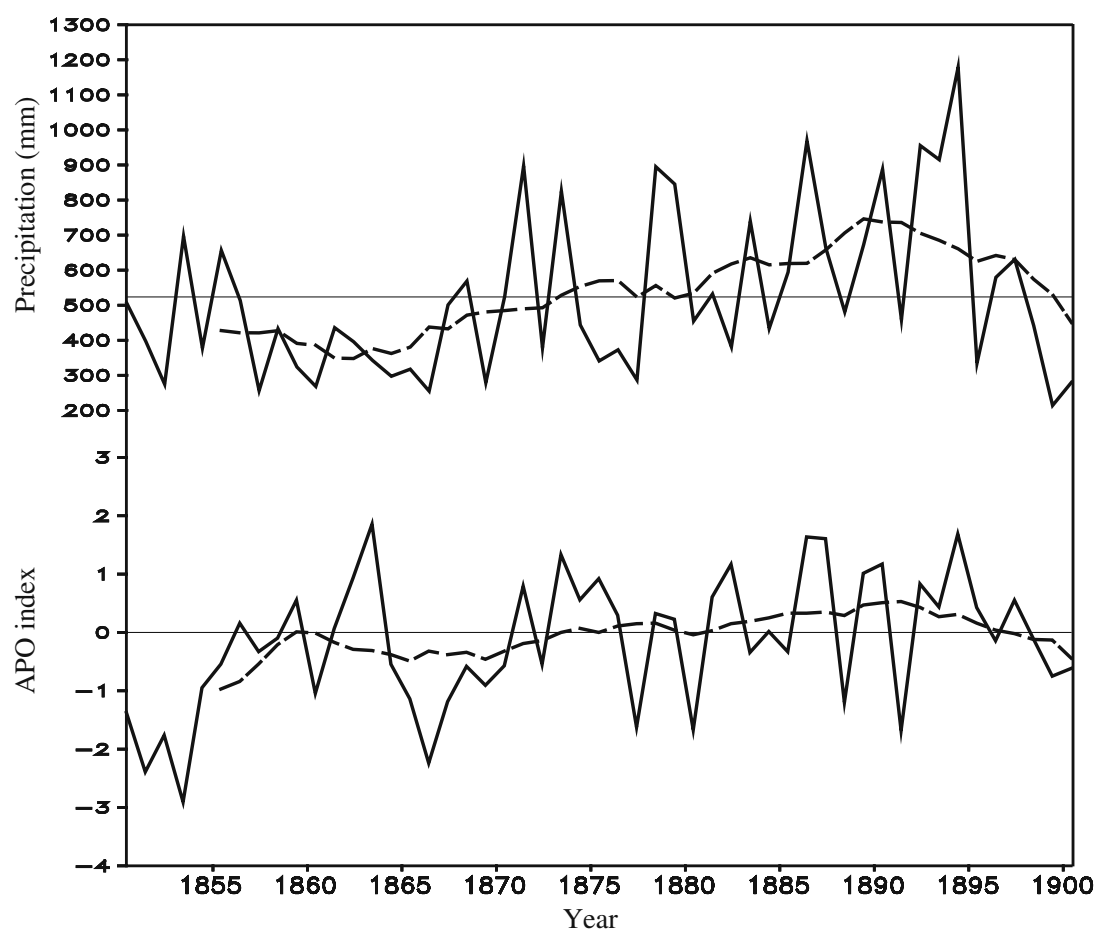

summer precipitation occurred in North China in the late nineteenth century.

From the foregoing analyses, on the decadal scale, the precipitation variability over eastern China is closely associated with APO over the past 150 years. During the earlier decades of the twentieth century, corresponding to a higher APO index, there were more rainfall to the south of the Yangtze River and over North China and less rainfall over the Huaihe River valley. During the recent decades, this anomalous precipitation pattern showed a southward shift.

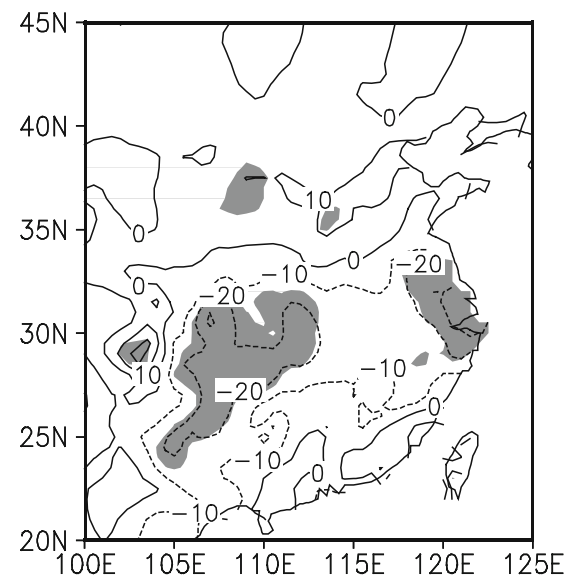

Fig. 10 Regressed CRU summer precipitation (mm) against the Guo's EASM index during 1961-2000. The shaded areas are at the $95 \%$ confidence level

\section{Summary and discussion}

Because of the shortness of long-term observations, some reconstructions of atmospheric circulation and climate proxy data over the EASM region have been done and applied to investigating the EASM variability. In this study, we reconstruct the summer middle-upper tropospheric temperature from SLP over the Asian-North Pacific sector during 1850-2004, calculating an atmospheric thermal contrast between Asia and the North Pacific (that is, the APO index) from the reconstructed temperature and examining the relationship of the APO index with SST over the Pacific and precipitation over eastern China during summer.

The results show that the summer middle-upper tropospheric temperature field may be well reconstructed from SLP during 1850-2004 by means of the PTR method. The APO phenomenon occurred in the reconstructed temperature field during earlier decades of 1850-2000, as it does in the recent decades. The reconstructed summer APO index shows inter-decadal variability during the past 150 years. Positive phases of the APO index mainly occurred in the $1870-1890$ s, the 1920s, and the 1940-1970s, indicating a stronger thermal contrast between Asia and the North Pacific; negative phases mainly emerged in the $1860 \mathrm{~s}$, the 1900-1910s, and the 1980-1990s, indicating a weaker thermal contrast.

The reconstructed APO index has significant correlations with SST over the Pacific during the past 150 years, with a 
significant positive correlation over the extratropical North Pacific and a significant negative correlation over the tropical central-eastern Pacific. These results are consistent with those from the recent observations, further verifying the reliability of the reconstructed APO index.

The variability of the APO index is highly correlated with the concurrent precipitation over eastern China on the decadal scale. Corresponding to a higher APO index in earlier decades of the twentieth century, summer precipitation anomalies over eastern China showed a +-+ pattern, with more rainfall appearing to the south of the Yangtze River and over North China and less rainfall appearing over the Huaihe River valley. In the recent decades, the summer precipitation anomalies also show the similar +-+ pattern. Compared to the earlier pattern, however, morerain and less-rain belts shifted southwards in the recent decades. In addition, for the period 1850-1900, the reconstructed APO index was possibly associated with precipitation in North China. For example, less precipitation in Beijing generally corresponded to a lower APO index during the $1850 \mathrm{~s}$ to the mid 1870 s, while more precipitation mainly corresponded to a higher APO index during the late 1870 s to the late 1890 s. These results show that summer APO may well reflect variations of rainfall over eastern China.

Because the APO index is derived from the SLP data, one may wonder whether the EASM index defined directly from SLP can better indicate variability of summer rainfall over eastern China. For this purpose, we calculate an EASM index defined from SLP (Guo 1983), called the Guo's EASM index. Figure 10 shows the regressed summer CRU precipitation against the Guo's EASM index during 1961-2000. In the figure, significant negative values appear in the upper and lower valleys of the Yangtze River, and no large-scale significant values appear over North China. Compared to the Guo' index, the reconstructed APO index may better reflect variability of summer precipitation over eastern China (Fig. 6a). Therefore, it needs more studies to reasonably define an EASM index from SLP for better describing summer precipitation over eastern China. Meanwhile, reconstructing such a thermal contrast index as APO is also a choice.

Acknowledgments We thank the Climate Diagnostic Center/NOAA for providing the NCEP-NCAR reanalysis data on its homepage, the Climatic Research Unit (CRU) at the University of East Anglia for providing precipitation on its homepage, and the National Climate Center of China Meteorological Administration for providing precipitation data in Beijing and Tianjin, China. We also thank Prof. Zhang De-Er in the National Climate Center of China Meteorological Administration for providing the reconstructed precipitation in Beijing. This work is jointly sponsored by the National Natural Science Foundation of China (40890052; 40890053), the Chinese COPES project (GYHY200706005), and the National Key Basic Research Project of China (2009CB421404).
Open Access This article is distributed under the terms of the Creative Commons Attribution Noncommercial License which permits any noncommercial use, distribution, and reproduction in any medium, provided the original author(s) and source are credited.

\section{References}

Allan RJ, Ansell TJ (2006) A new globally complete monthly historical mean sea level pressure data set (HadSLP2): 18502004. J Clim 19:5816-5842

Barnett TP, Preisendorfer R (1987) Origins and levels of monthly and seasonal forecast skill for United States surface air temperatures determined by canonical correlation analysis. Mon Wea Rev 115:1825-1850

Chang CP, Zhang Y, Li T (2000) Interannual and interdecadal variations of the East Asian summer monsoon and tropical Pacific SSTs. Part II: meridional structure of the monsoon. J Clim 13:4326-4340

Christiansen T, Schmith T, Thejll P (2009) A surrogate ensemble study of climate reconstruction methods: stochasticity and robustness. J Clim 22:951-976

Cook ER, Briffa KR, Jones PD (1994) Spatial regression methods in dendroclimatology - a review and comparison of two techniques. Int J Climatol 14:379-402

Ding YH (2004) Seasonal March of the East-Asian summer monsoon. In: Chang CP (ed) East Asian Monsoon. World Scientific, Singapore, pp 3-53

Ding YH, Wang ZY, Sun Y (2008) Inter-decadal variation of the summer precipitation in East China and its association with decreasing Asian summer monsoon. Part I: Observed evidences. Int J Climatol 28:1139-1161

Gong DY, Ho CH (2002) Shift in the summer rainfall over the Yangtze River valley in the late 1970s. Geophys Res Lett 29 (10): 1436

Gong DY, Wang SW (2000) Experiments on the reconstruction of historical monthly mean Northern Hemispheric $500 \mathrm{hPa}$ heights from surface data (in Chinese). J Trop Meteor 16:148-154

Gong DY, Drange H, Gao YQ (2007) Reconstruction of Northern Hemisphere $500 \mathrm{hPa}$ geopotential heights back to the late 19th century. Theor Appl Climatol 90:83-102

Guo QY (1983) The summer monsoon intensity index in East Asia and its variation (in Chinese). Acta Geogr Sin 38:207-217

Kalnay E, Kanamitsu M, Kistler R et al (1996) The NCEP/NCAR 40year reanalysis project. Bull Amer Meteor Soc 77:437-470

Klein WH, Dai Y (1998) Reconstruction of monthly mean 700-mb heights from surface data by reverse specification. J Clim 11:2136-2146

Krishnamurti TN, Surgi N (1987) Observational aspects of summer monsoon. In: Chang CP, Krishnamurti TN (eds) Monsoon meteorology. Oxford University Press, New York, pp 3-25

Lau KM, Li MT (1984) The monsoon of East Asia and its global associations - a survey. Bull AM Meteor Soc 65:114-125

Li C, Yanai M (1996) The onset and interannual variability of the Asian summer monsoon in relation to land-sea thermal contrast. J Clim 9:358-375

Liu Y, Park WK, Cai QF, Seo JW, Jung HS (2003) Monsoonal precipitation variation in the East Asia since A.D. 1840. Sci China Ser D-Earth 46:1031-1039

Liu Y, Cai Q, Liu W, Yang Y, Sun J, Song H, Li X (2008) Monsoon precipitation variation recorded by tree-ring $\delta^{18} \mathrm{O}$ in arid Northwest China since AD 1878. Chem Geol 252:56-61 
Luterbacher J, Schmutz C, Gyalistras D, Xoplaki E, Wanner H (1999) Reconstruction of monthly NAO and EU indices back to AD 1675. Geophys Res Lett 26:2745-2748

Mantua NJ, Hare SR, Zhang Y et al (1997) A Pacific interdecadal climate oscillation with impacts on salmon production. Bull Amer Meteor Soc 78:1069-1079

Massy WF (1965) Principal components regression in exploratory statistical research. J Amer Stat Assoc 60:234-256

Mu QZ, Wang SW, Zhu JH et al (2001) Variations of the western Pacific subtropical high in summer during the last hundred years (in Chinese). Chin J Atmos Sci 25:787-797

Murakami M, Ding H (1982) Wind and temperature changes over Eurasia during the early summer of 1979. J Meteor Soc Jpn 60:183-196

New M, Hulme M, Jones P (2000) Representing twentieth-century space-time climate variability. Part I: development of a 1901-96 monthly grids of terrestrial surface climate. J Clim 13:2217-2238

Prohaska JT (1976) A technique for analyzing the linear relationships between two meteorological fields. Mon Wea Rev 104:1345-1353

Quenouille MH (1952) Associated measurements. Butterworths, London, p 241

Smith TM, Reynolds RW, Peterson TC et al (2007) Improvements to NOAA's historical merged land-ocean surface temperature analysis (1880-2006). J Clim 21:2283-2296

Wang YX, Zhao P, Yu RC (2009) Inter-decadal variability of Tibetan spring vegetation and its associations with Eastern China spring rainfall. Inter J Climatol. doi:10.1002/joc.1939

Webster PJ, Yang S (1992) Monsoon and ENSO: selectively interactive systems. Q J Roy Meteor Soc 118:877-926

Weng H, Lau KM, Xue Y (1999) Multi-scale summer rainfall variability over China and its long-term link to global sea surface temperature variability. J Meteor Soc Jpn 77:845-857

Yang F, Lau KM (2004) Trend and variability of China precipitation in spring and summer: linkage to sea-surface temperatures. Int $\mathrm{J}$ Climatol 24:1625-1644
Yang YD, Man ZM, Zheng JY (2006) The grade reconstruction of 1711-1911 precipitation during the rainy season in Kunming and its preliminary study: a exploitation of archives (in Chinese). Geogr Res 25:1041-1049

Zhan RF, Li JP (2008) Influence of atmospheric heat sources over the Tibetan Plateau and the tropical western North Pacific on the inter-decadal variations of the stratosphere-troposphere exchange of water vapor. Sci China Ser D-Earth Sci 51:1179-1193

Zhang DE, Liu YW (2002) A new approach to the reconstruction of temporal rainfall sequences from 1724-1904 Qing Dynasty weather records for Beijing (in Chinese). Quaternary Sci 22:199-208

Zhang Y, Li T, Wang B (2004) Decadal change of the spring snow depth over the Tibetan plateau: The associated circulation and influence on the East Asian summer monsoon. J Clim 17:2780-2793

Zhao P, Zhang XD, Zhou XJ et al (2004) The sea ice extent anomaly in the North Pacific and its impact on the East Asian summer monsoon rainfall. J Clim 17:3434-3447

Zhao P, Zhu YN, Zhang RH (2007) An Asian-Pacific teleconnection in summer tropospheric temperature and associated Asian climate variability. Clim Dyn 29:293-303

Zhao P, Chen JM, Xiao D et al (2008) Summer Asian-Pacific Oscillation and its relationship with atmospheric circulation and monsoon rainfall. Acta Meteor Sin 22:455-471

Zhao P, Yang S, Yu RC (2010) Long-term changes in rainfall over eastern China and large-scale atmospheric circulation associated with recent global warming. J Clim 23:1544-1562

Zhao P, Cao ZH, Chen JM (2009) A summer teleconnection pattern over the extratropical Northern Hemisphere and associated mechanisms. Clim Dyn. doi:10.1007/s00382-0090699-0

Zhou BT, Zhao P, Cui X (2010) Linkage between the Asian-Pacific Oscillation and the sea surface temperature in the North Pacific. Chin Sci Bull 55:1193-1198 